Relations industrielles

Industrial Relations

\title{
Pourquoi et comment déléguer, par Roland Claude, Paris, Entreprise Moderne d'Édition, Collection Cadréco, no 10, 1969, 142 pp.
}

\section{Laurent Bélanger}

Volume 25, numéro 3, 1970

URI : https://id.erudit.org/iderudit/028170ar

DOI : https://doi.org/10.7202/028170ar

Aller au sommaire du numéro

Éditeur(s)

Département des relations industrielles de l'Université Laval

ISSN

0034-379X (imprimé)

1703-8138 (numérique)

Découvrir la revue

Citer ce compte rendu

Bélanger, L. (1970). Compte rendu de [Pourquoi et comment déléguer, par Roland Claude, Paris, Entreprise Moderne d'Édition, Collection Cadréco, no 10, 1969, 142 pp.] Relations industrielles / Industrial Relations, 25(3), 628-628. https://doi.org/10.7202/028170ar

Tous droits réservés (c) Département des relations industrielles de l'Université Laval, 1970
Ce document est protégé par la loi sur le droit d'auteur. L’utilisation des services d’Érudit (y compris la reproduction) est assujettie à sa politique d'utilisation que vous pouvez consulter en ligne.

https://apropos.erudit.org/fr/usagers/politique-dutilisation/ 
du Code du travail et de la Loi de la fonction publique, a fait le plus d'effort en vue de trouver une solution aux problèmes des rapports collectifs des salariés professionnels, quoique, depuis, le gouvernement central ait emboîté le pas et que, dans d'autres provinces, des commissions d'enquête aient étudié la question ou des projets de lois aient été ébauchés.

Ces quelques faits ne donnent qu'une pâle image de la valeur du travail de Mme Goldenberg qui, non seulement constitue un instrument essentiel pour ceux qui ont à appliquer la législation du travail telle qu'elle existe présentement aux diverses catégories professionnelles ou à mettre au point des lois et des réglementations nouvelles, mais est de nature à aider tous ceux qui s'intéressent aux problèmes du travail à se former une opinion sérieuse sur un phénomène nouveau de la vie sociale.

\section{André ROY}

Pourquoi et comment déléguer, par Roland Claude, Paris, Entreprise Moderne d'Edition, Collection Cadréco, no 10, 1969, 142 pp.

On reçonnaît facilement qu'uncun système d'organisation n'est viable et qu'aucune activité commune n'est possible sans une délégation de l'autorité. C'est tellement vrai qu'on peut attribuer la disparition de quelques petites et moyennes entreprises québécoises à l'incapacité du chef ou du propriétaire de déléguer un peu de son autorité à ses collaborateurs immédiats. Savoir déléguer judicieusement son autorité est une qualité qu'un administrateur peut acquérir ou améliorer. Dans cette optique, une lecture rapide de ce petit volume de la Collection Cadreco peut être grandement utile. Il tente de répondre aux questions fondamentales telles que: « Comment déléguer? - Comment choisir la personne à qui on veut déléguer son autorité ? - Quels sont les types d'autorité qui peuvent être délégués? Quelle est la latitude qu'on peut accorder à celui à qui on délègue son autorité ?

$\mathrm{Au}$ premier abord, le volume nous apparaît comme un recueil de recettes, mais cette impression se dissipe rapidement, lorsqu'on s'arrête aux idées principales clairement exprimées qui sont autant de réflexions profondes sur chacune des questions soulevées. C'est aussi un recueil et une mise en ordre intelligente de l'information éparse qu'on retrouve sur le sujet dans les différents ouvrages d'administration.

\section{Laurent BELANGER}

\section{Comment rédiger vos rapports, par Geor-} ges Bousquie, Paris, Entreprise Moderne d'Edition, Collection Cadréco, no 11 , (8e édition - 50e mille) 1970 , $150 \mathrm{pp}$.

A l'heure où la qualité de la communication dans l'entreprise moderne prend une importance telle qu'elle a des répercussions sur tous les aspects de ses activités, aussi bien sur la production que sur la mise en marché en passant par les relations du travail, ce petit livre vient apporter de judicieux conseils sur la façon de rédiger divers types de rapports.

Sa valeur tient surtout au fait qu'il est le fruit de l'expérience.

D'ailleurs de nombreux exemples de rapports aussi variés que concis viennent illustrer la façon dont on peut communiquer des renseignements relatifs à divers aspects de la vie de l'entreprise tels que: bris de machine, accident du travail, présentation d'un nouveau produit, etc.

\section{Jean BERNIER}

Le perfectionnement des cadres dirigeants et les politiques et pratiques en matière d'administration du personnel en Asie, Relations professionnelles, \# 35, Genève, B.I.T., 1969, 141 pp.

Le présent numéro de la série Relations professionnelles nous est présenté comme le compte rendu des travaux de la Commission du perfectionnement des cadres dirigeants à l'occasion de la sixième Conférence régionale asienne de I'O.I.T., tenue à Tokyo du 2 au 14 septembre 1968.

L'ouvrage compte deux parties. D'abord le rapport sur \& le perfectionnement des cadres dirigeants $\gg$ préparé par le BIT pour servir de base à la 